Portland State University

PDXScholar

Relationship Between Social Anxiety \& Facebook Surveillance

Jordan J. Rasmussen

Portland State University

Follow this and additional works at: https://pdxscholar.library.pdx.edu/honorstheses Let us know how access to this document benefits you.

Recommended Citation

Rasmussen, Jordan J., "Relationship Between Social Anxiety \& Facebook Surveillance" (2017). University Honors Theses. Paper 448.

https://doi.org/10.15760/honors.445

This Thesis is brought to you for free and open access. It has been accepted for inclusion in University Honors Theses by an authorized administrator of PDXScholar. Please contact us if we can make this document more accessible: pdxscholar@pdx.edu. 
Relationship Between Social Anxiety \& Facebook Surveillance

by

\section{Jordan Rasmussen}

An undergraduate honors thesis submitted in partial fulfillment of the requirements for the degree of

Bachelor of Arts

in

University Honors

and

Communication

Thesis Adviser

Dr. Erin Spottswood

Portland State University 


\begin{abstract}
The advent of social media has created a new type of information seeking to reduce uncertainty: extractive information seeking, which refers to when people seek information about their target by perusing their online social media profiles. The social compensation hypothesis suggests that those who suffer from social anxiety in face-to-face contexts might use a computermediated communication context (such as Facebook) to mitigate their face-to-face anxiety. The goal of this study is to find a relationship between general social anxiety (GSA) and interpersonal electronic surveillance (IES), a type of extractive information seeking. Results from this study indicate that while there is a positive relationship between general social anxiety and extractive information seeking, the relationship was not statistically significant. Due to finding non-significant results, implications for future research should follow up on the possibility that extractive information seeking has become normative to the point that social anxiety no longer mediates extractive information seeking.

\section{Introduction}

As a social networking site (SNS), Facebook has specific design aspects that afford users opportunities to reduce uncertainty about target individuals. Facebook allows users to maintain personal profiles, negotiate face-to-face relationships in a computer-mediated environment, and view other users' profiles with anonymity (Tokunaga, 2011). Given its design, Facebook may provide a controlled and comfortable environment for people with high social anxiety to reduce uncertainty about others because they may perceive Facebook to be less anxiety inducing than face-to-face interactions (McCord, Rodebaugh, \& Levinson, 2011). Research has supported the conclusion that social anxiety can predict Facebook use (McCord et al., 2011). This literature review and subsequent research seeks to further explore the link between individuals who exhibit 
RUNNING HEAD: Relationship Between Social Anxiety \& Facebook Surveillance

social anxiety, their predisposition to reduce uncertainty on Facebook, and the satisfaction of their Facebook information seeking endeavors.

\section{Literature Review}

\subsection{Uncertainty Reduction Theory}

Uncertainty Reduction Theory (URT) specifically pertains to initial meetings between two individuals and how they reduce uncertainty about each other during their initial interactions. Uncertainty is experienced when one cannot predict or provide explanations for the other individual's behavior, thus building expectations for relationships is the primary reason why individuals reduce uncertainty (Knobloch, Satterlee, \& Didomenico 2010). Uncertainty is reduced when individuals self-disclose intimate details, conversely, the lack of self-disclosure can create uncertainty (Cheung, Chiu, \& Lee 2011). During the "entry phase" of a relationship (Berger \& Calabrese, 1975, p. 100) information is gathered with little consequence and little involvement. Uncertainty Reduction Theory posits that uncertainty leads to "information-seeking behavior, as individuals are motivated to monitor other people's behavior in social situations" and "engage in a variety of strategies to find out more about others, such as covert observation, asking questions, or communicating to encourage others to reveal more about themselves" (Gibbs, Ellison, \& Lai, 2011, pp. 72-73), this information is gathered in order to construct a predictive model of the new person's behavior.

Information seeking strategies refer to the ways in which individuals reduce their uncertainty about others, whether it be strangers, acquaintances, friends, or potential romantic partners. According to Berger and Calabrese's (1975) original explanation of information seeking there are three strategies of information seeking: passive, active, and interactive. Passive strategies form impression by observing a person interacting with others, active strategies are 
RUNNING HEAD: Relationship Between Social Anxiety \& Facebook Surveillance

impressions formed by asking a third party about a person, and interactive strategies gather information through face-to-face discussion with a person (Griffin et al., 2015). Active strategies include seeking information about a target without addressing the target directly, oftentimes exemplified as asking the target's friends about them (Courtois All, \& Vanwynsberghe, 2012). Interactive strategies involve gathering information through direct interaction, regardless if the interaction is computer-mediated or face-to-face.

To reduce uncertainty about a target's feelings or intentions, an individual can engage in information seeking behaviors to evaluate normative behavior of the target and to reduce potential risks of self-disclosing further with the target (Gibbs et al., 2011). Expectations are often informed through seeking information and then reciprocation of self-disclosure (Gibbs et al., 2011) and these relational expectations inform how the relationship will progress, if at all. Within established relationships, relational uncertainty stems from ambiguity regarding the nature and future of the relationship (Fox \& Anderegg, 2014), which can result in anxiety, distress, partner monitoring or relationship collapse (Len-Ríos et al., 2016; Tokunaga, 2011).

\subsection{Extractive Information Seeking}

Today, uncertainty reduction can take place on a variety of Information Communication Technologies (ICTs) as well as face-to-face. One of the more popular ICTs for uncertainty reduction is the social network site Facebook. Facebook is an open or semi-open system, depending on an individual's specific privacy settings (Antheunis et al., 2010), that is available for anyone over the age of 13. Facebook users first begin by designing a virtual presentation of themselves to meet their self-presentation goals within Facebook's design parameters by posting pictures, posting status updates, or otherwise providing personal information in order to capitalize on the networking opportunities that Facebook affords (Ellison et al., 2007). Research 
RUNNING HEAD: Relationship Between Social Anxiety \& Facebook Surveillance

has shown that Facebook users generally create a profile that communicates their real-life personality rather than an idealized personality because their Facebook network will hold them accountable for spreading false, idealized information about oneself (Back et al., 2010). Once personal information has been provided, users create and manage a visible network of offline relationships that transcends to their online Facebook profile (Ellison et al., 2007), but it also allows them to meet new people by joining virtual groups based on common interests and to learn about people's hobbies, interests, stay in touch with people's activities, and monitor relationships that connections have to other people in their Facebook network (Ellison et al., 2007; Fox \& Tokunaga, 2015). The Facebook timeline archives all posts that a person either posted themselves or were tagged in and these posts are semi-public, depending on the user's unique privacy settings (between friends, friends-of-friends, or public). Facebook allows for interaction either privately, through direct messaging, or publicly, posting to another's timeline or tagging them in status updates or pictures (Fox, Osborn, \& Warber, 2014). All of these public activities, from self-disclosing on a profile to publicly posting content to joining interest-oriented groups, result in a great deal of information that is available for other users to access and form impressions of each other on and off the site.

On a social networking site such as Facebook, information seeking strategies take a somewhat different form. On Facebook, active strategies would refer to surveying a target's Facebook friends to build expectations about their friend group and potentially asking those friends for information about the target (Fox \& Anderegg, 2014). Interactive strategies pertain to situations wherein target individuals have direct communication (Courtois et al., 2012), such as commenting on a target's post or sending a private message (Fox \& Anderegg, 2014). Passive strategies refer to non-intrusive observations of their target, such as monitoring another's profile 
RUNNING HEAD: Relationship Between Social Anxiety \& Facebook Surveillance

without any direct communication (Courtois et al., 2012). This may include reading the target's posts, sifting through their pictures, or simply observing their activity on Facebook (Fox \& Anderegg, 2014).

However, since Berger and Calabrese's original research in the 1970s, ICTs also allow for a new kind of information seeking: extractive information seeking. (Courtois et al., 2012). Extractive information seeking is a term that refers to passive information seeking on SNSs, extractive information seeking is essentially observing a target's behavior specifically online, whereas passive information seeking strategies refer to observation in face-to-face contexts. Research suggests that extractive information seeking via Facebook is a popular method of uncertainty reduction during early stages of a relationship because it allows individuals to reduce uncertainty at their own pace without having to make a good impression face-to-face (Fox et al., 2013). Research done on a Netherlands-based social networking site found that $98.9 \%$ of participants used extractive strategies the most in their attempts to reduce uncertainty about their target (Antheunis et al., 2010).

Facebook's affords a constant stream of abundant information that can be used to conduct extractive information seeking. This can be done by surveying another user's posting behavior, work history, dating history, social affiliations, academic history, and more (Tokunaga, 2011). The combination of these posts, histories, interactions, pictures, and posts on Facebook provide individuals with digital examples of target behavior to create a model of expected behaviors for their target and inform feelings about the target (Fox et al., 2014). Research has shown that over $60 \%$ of college students use Facebook to engage in surveillance - a kind of extractive information seeking - of their significant others and colleagues on the site (Stern \& Taylor, 2007) which has been called Interpersonal Electronic Surveillance (IES) (Tokunaga, 2011). Examples 
RUNNING HEAD: Relationship Between Social Anxiety \& Facebook Surveillance

of Facebook surveillance include surveying classmates' profiles for potential romantic compatibility and repeated monitoring of their romantic partner's activity on Facebook (Stern \& Taylor, 2007). In the context of newly formed relationships with acquaintances, uncertainty often arises as individuals work out the norms and expectations within the relationship. This uncertainty can be reduced via extractive information seeking (Fox \& Anderegg., 2014) without having to interact directly with the target. This allows users to obtain information and reduce uncertainty without alerting the target, which can be a real benefit to people who experience social anxiety when interacting directly with other people (Courtois et al., 2012).

\subsection{Social Anxiety and Facebook Use}

Research has demonstrated that extractive information seeking on Facebook is the preferred method of information gathering for individuals with social anxiety (Fox \& Tokunaga, 2015; Oldmeadow et al., 2013; White et al., 2015). Social anxiety is defined “an individual's level of fear or anxiety associated with either real or anticipated communication with another person or persons" (White et al., 2015, p. 24). For example, individuals can experience social anxiety in a variety of contexts such as giving a public speech, speaking to a superior in an organizational environment, or when engaged in an unfamiliar interpersonal communication setting (White et al., 2015). Essentially, those who are socially anxious report themselves as being shy when engaged in an interpersonal setting (McCord et al., 2014) or feel some sort of apprehension to communicate with others (White et al., 2015).

The function of anxiety is to detect potential threats that may be outside of the individual's control (Xie \& Newhagen, 2012) and the social compensation hypothesis suggests that those who suffer from social anxiety in face-to-face contexts might use a computer-mediated communication context (such as Facebook) to mitigate their face-to-face anxiety (McCord et al., 
RUNNING HEAD: Relationship Between Social Anxiety \& Facebook Surveillance

2014; Fernandez et al., 2012). Facebook affords individuals the power to surreptitiously recognize and manage anxiety via IES (Fernandez et al., 2012). Individuals with social anxiety may "find it difficult to get to know someone, disclose information, and form a solid relationship" (Courtois et al., p. 6). There are many explanations as to why an individual with social anxiety may prefer to use Facebook to communicate, including the controllability and ability to rehearse conversations via private CMC messages over Facebook Messenger or selfpresenting in a way that would limit the possibility of other people negatively reacting to their Facebook profile. The problem that socially anxious individuals face may be overcome by using SNSs, but it is also possible that using SNSs contributes to social anxiety, loneliness, and may exacerbate feelings of face-to-face isolation, which warrants further study given the increasing popularity of Facebook (Fernandez et al., 2012; Kross et al., 2013).

McCord and colleagues (2014) used the Facebook-Social Interaction Anxiety Scale (FSIAS) to measure social anxiety that arises from Facebook's unique social interaction techniques (e.g. "I am unsure whether to send a friend request to someone I do not know very well yet" \& "I have difficulty commenting on someone's status or other post”; McCord et al., 2014, p. 25). McCord's (2014) research found that people with high social anxiety use Facebook's social interaction tools more than those with low social anxiety, suggesting that socially anxious individuals prefer Facebook to gather information, communicate, and selectively self-disclose rather than engaging in a face-to-face interaction, which participants described as less controllable and more stress/anxiety-inducing. To date, there have been many studies examining the relationship between social anxiety and Facebook information seeking strategies (Fernandez et al., 2012; Courtois et al., 2012; Tokunaga, 2011). This study will seek to examine this relationship further, specifically measuring how individuals with high general social anxiety 
RUNNING HEAD: Relationship Between Social Anxiety \& Facebook Surveillance

regarding face-to-face communication feel that their uncertainty is reduced after engaging in extractive information seeking via interpersonal electronic surveillance seeking on Facebook.

\subsection{Hypothesis}

H1: General social anxiety (GSA) is positively correlated with interpersonal electronic surveillance (IES)

\subsection{Method}

\subsection{Participants and Procedures}

Sixty-eight participants were recruited from a Northwest university’s Communications undergraduate pool and were compensated with extra credit for the courses in which the survey was distributed. Individuals who did not participate in the survey were offered an alternative extra credit assignment. Of the original sixty-eight, only fifty-nine $(N=59)$ respondents completed the survey in full. Within the final sample $71.2 \%$ identified as female $(M=.275, S D=$ $.45, n=42), 27 \%$ identified as male $(M=.275, S D=.45, n=16)$ and one participant did not disclose their gender $(3.4 \%)$. The mean age was $25.39(S D=7.64)$ and $67.8 \%$ of the participants were white $(M=1.64, \mathrm{SD}=1.3, n=40)$. Other ethnicities reported included Asian or Pacific Islander $(M=1.64, S D=1.3, n=3,5 \%$,$) , multiracial (M=1.64, S D=1.3, n=4,6.8 \%$,$) , Latinx$ $(M=1.64, S D=1.3, \mathrm{n}=2,3.4 \%)$, and Black $(M=1.64, S D=1.3, \mathrm{n}=8,13.6 \%)$, while two respondents did not disclose their ethnicity $(M=1.64, S D=1.33, n=2, .4 \%)$.

\subsection{Measures}

Participants were informed about an opportunity to take an online survey distributed in two separate undergraduate Communications courses. The participants were first asked to provide demographic information (race, gender, age, etc.) Participants then completed nine questions pertaining to general social anxiety, which set the basis for GSA, and online social 
RUNNING HEAD: Relationship Between Social Anxiety \& Facebook Surveillance

anxiety including "as I imagine spending time with strangers, I feel nervous and disturbed" and "as I imagine chatting with others on Facebook, I feel nervous" ("Social Interaction Anxiety Scale" measures adapted from Hong et al., 2015, $\alpha=.833$ ). The next set of questions ("The Facebook Questionnaire", $\alpha=.86 \&$ "Facebook-Social Interaction Anxiety Scale", $\alpha=.86$ adapted from McCord et al., 2014) assessed participant's general Facebook usage by asking questions such as "I post comments on friends' status updates, pictures, etc." (McCord et al., 2014). The next set of questions asked for the intensity of Facebook usage ("Facebook Intensity Scale" adapted from Ellison et al., 2007, $\alpha=.83$ ), asking questions like "In the past week, on average, approximately how many minutes per day have you spent on Facebook?" (Ellison et al., 2007). This was followed by a set of 14 questions that asked respondents to report their use of information seeking habits on a 5-point Likert scale, including "after becoming acquainted and becoming Facebook friends with someone you want to develop a relationship with (romantic, platonic, otherwise), how likely are you to look at their pictures." (Antheunis et al., 2010, $\alpha=$ .76). To measure interpersonal electronic surveillance, Tokunaga's (2011) ISS scale was used ( $\alpha$ $=.97)$.

The Social Interaction Anxiety Scale was found to be reliable for this data set ( 9 items, $\alpha$ $=.882$ ). The Facebook Questionnaire and Facebook-Social Interaction Anxiety Scale were found to be reliable for this sample (7 items, $\alpha=.84$ ). The Facebook Intensity Scale was also found to be reliable ( 8 items, $\alpha=.82$ ) for this sample. Antheunis et al.'s (2010) measure was was also reliable for this sample (14 items, $\alpha=.88)$. General social anxiety was measured using Hong and colleagues' adapted Social Interaction Anxiety Scale (2015; adapted from Mattick \& Clarke, 1998, Social Interaction Anxiety Scale). The GSA measure was found to be highly reliable (5 items; $\alpha=.84$ ) While Hong et al. (2015) extended the measure to include social anxiety in online 
settings, this research's hypothesis is not concerned with questions pertaining to online social anxiety, only the questions relating general social anxiety in face-to-face contexts, so the questions regarding online social anxiety were disregarded. The scale is based on a 5-point Likert scale with five indicating greater levels of social anxiety. The average GSA score was lower than the midpoint $(M=2.6, S D=1.04, n=59)$. Sample questions from the GSA include "as I imagine spending time with strangers, I feel nervous and disturbed" and "when attending a crowded social event, I want to escape back home immediately" (adapted from Hong et al., 2015). The IES (Tokunaga, 2011) was adapted as a 5-point Likert scale to match the GSA, its validity was established in Tokunaga's research (2011) and was highly reliable for this sample (15 items; $\alpha=.94$ ). The average score on the IES was lower than lower than the midpoint on the scale $(M=2.81, S D=.93, \mathrm{n}=59)$. Sample questions from the IES include: "after becoming acquainted and becoming Facebook friends with someone you want to develop a relationship with (romantic, platonic, otherwise), how likely are you to notice when they update their social networking site page" and "after becoming acquainted and becoming Facebook friends with someone you want to develop a relationship with (romantic, platonic, otherwise), how likely are you to peruse their Facebook page to see what they’re up to" (Tokunaga, 2011).

\subsection{Results}

A Spearman's rho correlation was used on the whole sample $(n=59)$ to ascertain the correlation between GSA and ISA because the sample was negatively skewed. There was no significant correlation between general social anxiety and interpersonal electronic surveillance (2.6 Spearman $\left.r_{s}=.153, p<.246, n=59, n s\right)$ throughout the entire sample. In observing the relationship between low general social anxiety and engagement in interpersonal electronic surveillance, the average score for low socially anxious respondents score was well below the 
RUNNING HEAD: Relationship Between Social Anxiety \& Facebook Surveillance

midpoint $(M=1.87, S D=.56)$ and the average IES score was as well $(M=2.74, S D=.96)$. The low GSA sample was normally distributed so a Pearson's correlation was used, finding a positive but statistically insignificant correlation between low general social anxiety respondents $(n=35)$ and interpersonal electronic surveillance $(r(33)=2.33, p<.197, n s)$. A Pearson's correlation was also used to observe the relationship between high GSA respondents $(n=24)$, who had an average GSA score of $3.68(S D=.5)$ and an average IES score of $2.9(\mathrm{SD}=.89)$. Interestingly, although a positive correlation was found for high GSA and IES $(r(22)=.18, p<.401, n s)$ the relationship was lower than the correlation for low GSA and IES thus the results are inconsistent with my hypotheses.

\subsection{Discussion}

This study tested models of general social anxiety (GSA) and interpersonal-electronic surveillance (IES) with the hypothesis that there would be a significant, positive correlation found between individuals with high levels of GSA and high levels of IES. While a positive relationship was found between high levels of GSA and IES the results were not significant, and thus the hypothesis was not supported. Furthermore, the relationship between low levels of GSA and high levels of IES was stronger than high GSA and high IES. Theoretically there should be a positive relationship according to the social compensation hypothesis which suggests that "people with high social anxiety are motivated to use Facebook to compensate for discomfort in face-to-face social interactions" (McCord et al., 2014, p. 26), however, this study found no significant relationship to support the social compensation hypothesis. Nonetheless, the results of this study can be explained by first describing the study's limitations and then exploring other potential factors that mediate the proposed relationship.

\subsection{Theoretical Implications and Future Research}


RUNNING HEAD: Relationship Between Social Anxiety \& Facebook Surveillance

Plenty of research has found a link between anxious-attachment styles and extractive information seeking and IES (Fox \& Tokunaga, 2015, Fox \& Anderegg, 2014) and found that the relationship is often mediated by jealousy (Drouin, Miller, \& Dibble, 2014). While the social compensation hypothesis (McCord et al., 2014; Rauch, Strobel, Bella, Odachowski, \& Bloom, 2014) also suggests that there is a positive relationship between social anxiety and extractive information seeking, it does not necessarily provide an explanation for that relationship other than the possibility that anxious individuals experience more stress when they are uncertain, and thus they turn to extractive information seeking to reduce uncertainty and thus their stress (LenRios et al., 2016; McCord et al., 2014). The current research was designed to support this hypothesis but the results did not align with the theoretical conclusions established by prior research. Research by Courtois et al. (2012) found that there social anxiety had no effects on uncertainty regarding acquaintances while other research found that extractive information seeking was most common before or after romantic relationships (Drouin et al., 2014; Fox \& Anderegg, 2014). It is possible that extractive information seeking has become an unspoken norm regardless of social anxiety or the type of relationship, but that people are only cognitively aware of their extractive information seeking when they seek information within the context of a romantic relationship. The present research did not make the distinction between acquaintances, friends, or romantic partners, so future research should test the relationship between extractive information seeking between various types of relationships to ascertain differences in how anxious individuals use Facebook to reduce uncertainty throughout their various types of relationships.

This research did not explore the possibility that IES actually increases anxiety and uncertainty for high GSA individuals. Focus groups ran by Len-Rios et al. (2016) found that 
RUNNING HEAD: Relationship Between Social Anxiety \& Facebook Surveillance

“individuals preferred not knowing anything negative about their partner so as not to hurt their relationship" (p. 10). Keeping in mind URT, if negative information could be dredged up through passive information seeking and IES, then individuals with high levels of GSA might actually prefer to abstain from passive information seeking on Facebook to mitigate any potential uncertainty or stress caused by obtaining negative information (Len-Rios et al., 2016; McCord et al., 2014). For example, Len-Rios et al. (2016) identified three sources of negative information that could deter people from engaging in extractive information seeking on Facebook: out of context pictures, possible misinterpretations of comments between the dyad, and comments from third-parties that could threaten the relationship. The combination of these factors resulted in people avoiding Facebook "because there might be information there that they really do not want to know" (Len-Rios et al., 2016, p. 10) Furthermore, because of selective, idealized selfpresentation on SNSs, research by Mehdizadeh (2010) found idealized self-presentation could result in people being distrustful of the information they find online because it might not be representative of the actual person. Selective self-presentation could be due to the need for privacy or due to the need to "maintain emotional balance" (Nitzburg \& Farber, 2013, p. 1189). Thus, future research should explore other mediating relationships that predict extractive information seeking. For example, jealousy or anxious attachment styles may be factors that are more predictive of extractive information seeking (Muise et al., 2013; Fox \& Tokunaga, 2015).

\subsection{Limitations}

First, because socially anxious individuals are characterized by "communication apprehension" (Pearson et al., 2011; White et al., 2015), it is possible that survey respondents with high social anxiety were afraid to truthfully answer the questions pertaining to IES. This would be potentially indicative of desirability bias within the high GSA respondents because IES 
RUNNING HEAD: Relationship Between Social Anxiety \& Facebook Surveillance

is more colloquially known as "Facebook Stalking" which, as of now, has negative connotations

(Fox \& Anderegg, 2014). The consent form at the beginning of the survey (Appendix A) could've primed participant's negative feelings toward Facebook stalking and influenced the results because it is possible that terms like "Facebook usage and habits", "satisfaction from using Facebook", and "how people learn about others via Facebook" could've primed participants into responding dishonestly in order to meet self-presentation goals because of the negative connotations surrounding Facebook "stalking” or "creeping” (Muise, Christofides \& Desmarais, 2013).

The study's sample characteristics and size has major implications on the validity and generalizability of the results. There were less highly socially anxious participants $(n=24)$ than low socially anxious participants $(n=35)$, so the data could be skewed because the sample sizes are too small to draw any conclusions, thus these results are not generalizable. Furthermore, the sample was conveniently collected within two undergraduate communication courses. Future research should measure the relationship between social anxiety and extractive information seeking but with a much larger, more representative sample that is not entirely comprised of communication students. Also, this research did not ask about extractive information seeking on other SNS platforms, like Twitter or Instagram, only Facebook. While $79 \%$ of all online adults use Facebook (Greenwood, Perrin, \& Duggan, 2016), it is very possible that people prefer to engage in IES on other social media platforms, so future research should also explore the information seeking habits on those platforms.

\subsection{Conclusion}

In conclusion, while extractive information seeking and IES is fairly normalized, because a negative stigma persists regarding extractive information seeking (Fox \& Anderegg, 2014; 
RUNNING HEAD: Relationship Between Social Anxiety \& Facebook Surveillance

Muise et al., 2013) it is possible that for this research's sample, socially anxious respondents were apprehensive to self-report their IES habits (Muise et al., 2013). Due to the normativity of extractive information seeking, the results of this study also suggest that social anxiety may no longer be a viable explanation for extractive information seeking. While the relationship between social anxiety and extractive information seeking has been demonstrated in past research (McCord et al., 2014; Len-Ríos et al., 2016; Tokunaga, 2011; Fox et al., 2014; Gibbs et al., 2011) the ubiquity of social media continues to increase the normalization extractive information seeking, dramatically changing the way people reduce uncertainty and the way individuals create, develop, and maintain their interpersonal relationships (Fox et al., 2014).

\section{Acknowledgements}

The quantitative analysis for this project could not have been completed without the support, advice, and friendship of Sam Reynolds. 


\section{References}

Antheunis, M. L., Valkenburg, P. M., \& Peter, J. (2010). Getting acquainted through social network sites: Testing a model of online uncertainty reduction and social attraction. Computers in Human Behavior, 26(1), 100-109.

doi:10.1016/j.chb.2009.07.005

Back, M. D., Stopfer, J. M., Vazire, S., Gaddis, S., Schmukle, S. C., Egloff, B., \& Gosling, S. D. (2010). Facebook profiles reflect actual personality, not self-idealization. Psychological Science, 21(3), 372-374. doi:10.1177/0956797609360756

Berger, C. R., \& Calabrese, R. J. (1975). Some Explorations In Initial Interaction And Beyond: Toward A Developmental Theory Of Interpersonal Communication. Human Communication Research, 1(2), 99-112. doi:10.1111/j.1468-2958.1975.tb00258.x

Cheung, C. M., Chiu, P., \& Lee, M. K. (2011). Online social networks: Why do students use facebook? Computers in Human Behavior, 27(4), 1337-1343.

doi:10.1016/j.chb.2010.07.028

Courtois, C., All, A., \& Vanwynsberghe, H. (2012). Social Network Profiles as Information Sources for Adolescents' Offline Relations. Cyberpsychology, Behavior, and Social Networking, 15(6), 290-295. doi:10.1089/cyber.2011.0557

Drouin, M., Miller, D. A., \& Dibble, J. L. (2014). Ignore your partners' current Facebook friends; beware the ones they add! Computers in Human Behavior, 35, 483-488.

doi:10.1016/j.chb.2014.02.032

Ellison, N. B., Steinfield, C., \& Lampe, C. (2007). The Benefits of Facebook "Friends:" Social Capital and College Students' Use of Online Social Network Sites. Journal of 
Computer-Mediated Communication, 12(4), 1143-1168. doi:10.1111/j.10836101.2007.00367.x

Fernandez, K. C., Levinson, C. A., \& Rodebaugh, T. L. (2012). Profiling: Predicting Social Anxiety From Facebook Profiles. Social Psychological and Personality Science, 3(6), 706-713. doi:10.1177/1948550611434967

Fox, J., \& Anderegg, C. (2014). Romantic Relationship Stages and Social Networking Sites: Uncertainty Reduction Strategies and Perceived Relational Norms on Facebook. Cyberpsychology, Behavior, and Social Networking, 17(11), 685-691.

doi:10.1089/cyber.2014.0232

Fox, J., Warber, K. M., \& Makstaller, D. C. (2013). The role of Facebook in romantic relationship development: An exploration of Knapp's relational stage model. Journal of Social and Personal Relationships, 30(6), 771-794. doi:10.1177/0265407512468370

Fox, J., Osborn, J. L., \& Warber, K. M. (2014, March 17). Relational dialectics and social networking sites: The role of Facebook in romantic relationship escalation, maintenance, conflict, and dissolution. Computers in Human Behavior, 35, 527-534.

doi:10.1016/j.chb.2014.02.031

Fox, J., \& Tokunaga, R. S. (2015, November 9). Romantic Partner Monitoring After Breakups: Attachment, Dependence, Distress, and Post-Dissolution Online Surveillance via Social Networking Sites. Cyberpsychology, Behavior, and Social Networking, 18(9), 491-498. doi:10.1089/cyber.2015.0123

Gibbs, J. L., Ellison, N. B., \& Lai, C. (2011). First comes love, then comes google: an investigation of uncertainty reduction strategies and self-disclosure in online dating. Communication Research, 38(1), 70-100. doi:10.1177/0093650210377091 
Greenwood, S., Perrin, A., \& Duggan, M. (2016, November 11). Social Media Update 2016. Retrieved from http://www.pewinternet.org/2016/11/11/social-media-update-2016/

Hong, J., Hwang, M., Hsu, C., Tai, K., \& Kuo, Y. (2015, July). Belief in dangerous virtual communities as a predictor of continuance intention mediated by general and online social anxiety: The Facebook perspective. Computers in Human Behavior, 48, 663-670. doi:10.1016/j.chb.2015.02.019

Knobloch, L. K., Satterlee, K. L., \& Didomenico, S. M. (2010). Relational uncertainty predicting appraisals of face threat in courtship: Integrating uncertainty reduction theory and politeness theory. Communication Research,37(3), 303-334.

doi:10.1177/0093650210362527

Kross E, Verduyn P, Demiralp E, Park J, Lee DS, et al. (2013) Facebook Use Predicts Declines in Subjective Well-Being in Young Adults. PLOS ONE 8(8): e69841. https://doi.org/10.1371/journal.pone.0069841

Len-Ríos, M. E., Streit, C., Killoren, S., Deutsch, A., Cooper, M. L., \& Carlo, G. (2016). US Latino adolescents use of mass media and mediated communication in romantic relationships. Journal of Children and Media, 1-16.

doi:10.1080/17482798.2016.1144214

Mattick, R. P., \& Clarke, J. (1998). Development and validation of measures of social phobia scrutiny fear and social interaction anxiety. S.T. Behaviour Research and Therapy, 36(4), 455-470. doi:10.1016/s0005-7967(97)10031-6 
McCord, B., Rodebaugh, T. L., \& Levinson, C. A. (2014, February 21). Facebook: Social uses and anxiety. Computers in Human Behavior, 34, 23-27.

doi:10.1016/j.chb.2014.01.020

Mehdizadeh, S. (2010). Self-presentation 2.0: Narcissism and self-esteem on Facebook. Cyberpsychology, Behavior, and Social Networking, 13(4), 357-364.

doi:10.1089/cpb.2009.0257

Muise, A., Christofides, E., \& Desmarais, S. (2013). “Creeping” or just information seeking? Gender differences in partner monitoring in response to jealousy on Facebook. Personal Relationships, 21(1), 35-50. doi:10.1111/pere.12014

Nitzburg, G. C., \& Farber, B. A. (2013). Putting up emotional (Facebook) walls? Attachment status and emerging adults' experiences of social networking sites. Journal of Clinical Psychology, 69(11), 1183-1190. doi:10.1002/jclp.22045

Oldmeadow, J. A., Quinn, S., \& Kowert, R. (2012, November 13). Attachment style, social skills, and Facebook use amongst adults. Computers in Human Behavior, 29(3), 1142-1149. doi:10.1016/j.chb.2012.10.006

Pearson, J. C., Child, J. T., Degreeff, B. L., Semlak, J. L., \& Burnett, A. (2011). The Influence of Biological Sex, Self-Esteem, and Communication Apprehension on Unwillingness to Communicate. Atlantic Journal of Communication, 19(4), 216-227. doi:10.1080/15456870.2011.584509

Rauch, S. M., Strobel, C., Bella, M., Odachowski, Z., \& Bloom, C. (2014). Face to face versus Facebook: Does exposure to social networking web sites augment or attenuate 
RUNNING HEAD: Relationship Between Social Anxiety \& Facebook Surveillance

physiological arousal among the socially anxious? Cyberpsychology, Behavior, and Social Networking, 17(3), 187-190. doi:10.1089/cyber.2012.0498

Stern, L.A. \& Taylor, K., (January, 2007). 'Social networking on Facebook', Journal of the Communication, Speech \& Theatre Association of North Dakota 20, 9-20.

Tokunaga, R. S. (2011). Social networking site or social surveillance site? Understanding the use of interpersonal electronic surveillance in romantic relationships. Computers in Human Behavior, 27(2), 705-713. doi:10.1016/j.chb.2010.08.014

Tong, S. T. (2013, November 11). Facebook Use During Relationship Termination: Uncertainty Reduction and Surveillance. Cyberpsychology, Behavior, and Social Networking, 16(11), 788-793. doi:10.1089/cyber.2012.0549

White, K. H., Howard, M. C., Zhong, B., Soto, J. A., Perez, C. R., Lee, E. A., . .

Minnick, M. R. (2015). The Communication Anxiety Regulation Scale: Development and Initial Validation. Communication Quarterly, 63(1), 23-43.

doi:10.1080/01463373.2014.965836

Xie, W., \& Newhagen, J. E. (2012). The Effects of Communication Interface Proximity on User Anxiety for Crime Alerts Received on Desktop, Laptop, and Hand-Held Devices. Communication Research, 41(3), 375-403. doi:10.1177/0093650212448670

\section{Appendix A}

You are being invited to participate in a research study about general social anxiety and Facebook habits. This study is being conducted by Jordan Rasmussen and Dr. Spottswood, from the Communications Department at Portland State University. The study is being conducted for Rasmussen's Undergraduate Thesis in the Honors College. 
There are no known risks if you decide to participate in this research study. There are no costs to you for participating in the study. The information you provide will help researchers measure general social anxiety of participants, their Facebook usage and habits, and their satisfaction from using Facebook in conjunction with a larger study focusing on how people learn about others via Facebook. The questionnaire will take anywhere from 5 to 10 minutes to complete. The information collected may not benefit you directly, but the information learned in this study should provide an opportunity to gain self-awareness and will contribute to the research community's growing understanding of Facebook.

This survey is anonymous and IP addresses are not tracked, although absolute anonymity cannot be guaranteed over the Internet. No one will be able to identify you or your answers, and no one will know whether or not you participated in the study. Individuals from the Institutional Review Board may inspect these records. Should the data be published, no identifying information will be disclosed.

Your participation in this study is voluntary. By clicking "accept" at the end of this form, you are voluntarily agreeing to participate.

If you have any questions about the study, please contact Jordan Rasmussen at rasmus7@pdx.edu or Dr. Spottswood at e.1.spottswood@pdx.edu 
The Portland State University Institutional Review Board has reviewed this project. If you have any concerns about your rights in this study, please contact the PSU Office of Research Integrity at (503) 725-2227 or email hsrrc@ pdx.edu.

By clicking "accept" at the end of this form, you are consenting to participate in this survey. IF you do not consent, please click "decline" to navigate away from the survey. 